\title{
Pathological changes in cultured channel catfish Ictalurus punctatus spontaneously infected with Streptococcus iniae
}

\author{
De-fang Chen ${ }^{1,2}$, Kai-yu Wang ${ }^{1,3, *}$, Yi Geng ${ }^{1,3}$, Jun Wang ${ }^{2}$, Xiao-li Huang ${ }^{2}$, Ming He ${ }^{1}$ \\ ${ }^{1}$ Department of Basic Veterinary, College of Veterinary Medicine, ${ }^{2}$ Department of Aquaculture, College of Animal Science \& \\ Technology, and ${ }^{3}$ Key Laboratory of Animal Disease and Human Health of Sichuan Province, Sichuan Agricultural \\ University, Ya'an 625014, Sichuan, PR China
}

\begin{abstract}
The pathological changes present in channel catfish Ictalurus punctatus spontaneously infected by Streptococcus iniae are described. The most consistent gross findings were marked petechial hemorrhages of the skin and congestion of internal organs, particularly the liver, spleen and kidneys. Other features included color fading at the edge of fin rays, enteritis and ascites. Histological examination showed oedema, degeneration and necrotic changes in many organs. Further, hepatitis, splenitis, interstitial nephritis, and meningitis with numerous monocyte and neutrocyte infiltrates were evident. Intact $S$. iniae cells were seen in macrophages. Apparently, spontaneous $S$. iniae infection caused acute septicaemia in channel catfish. This is the first histopathological report on channel catfish naturally infected with $S$. iniae.
\end{abstract}

KEY WORDS: Histopathology $\cdot$ Channel catfish $\cdot$ Streptococcus iniae

\section{INTRODUCTION}

Channel catfish Ictalurus punctatus were first introduced into China in 1978 and were initially considered to be resistant to common infectious diseases. In the past $30 \mathrm{yr}$, Channel catfish has become one of the major freshwater aquaculture species in China and an important component of the food fish export trade (Wang et al. 2008). However, the occurrence of various diseases has limited the sustainable development of the industry in China. Identification of the pathogens and their pathogenesis will be crucial for the control of these infectious diseases and further growth of catfish production in China.

Streptococcus iniae has become one of the most serious aquatic pathogens in the last decade, and can cause high losses in farmed marine and freshwater finfish in warmer regions. Infection by $S$. iniae has been documented in a number of species of fish, such as barramundi Lates calcarifer (Creeper \& Buller 2006), tilapia Oreochromis spp. (Shoemaker et al.
2001), and rainbow trout Oncorynchus mykiss (Lahav et al. 2004), as well as in mammals (Pier \& Madin 1976, Facklam et al. 2005). However, resistance to infection has also been reported in some species, such as channel catfish (Robinson \& Meyer 1966, Shoemaker et al. 2001).

Between 2006 and 2007, a streptococcal infection occurred in cultured channel catfish at fish farms in Guangxi, China. Our previous research demonstrated that the agent of streptococcal infection in channel catfish was Streptococcus iniae (Chen et al. 2011). Although there was a report describing the histopathology of Streptococcus sp. infection in channel catfish (Chang \& Plumb 1996), there is no information in the literature on the histopathology of $S$. iniae infection in channel catfish.

In this study, we describe the pathogenic characteristics of spontaneous infection with Streptococcus iniae in cultured channel catfish in China. Our data indicate that infection of channel catfish with $S$. iniae causes necrotic inflammation in multiple organs. 


\section{MATERIALS AND METHODS}

Approximately 200 diseased channel catfish were collected from a commercial aquaculture farm in Guangxi province, where catfish were affected by an outbreak of streptococcosis. These fish had a body weight of between 100 and $150 \mathrm{~g}$ and were farmed in reservoir cages at densities of $200 \mathrm{fish}^{-3}$. All of these fish were used for observation of clinical symptoms and anatomy. The water temperature was between 24 and $28^{\circ} \mathrm{C}$ when the streptococcus infection occurred. The mortality rate was between 30 and $90 \%$. The channel catfish had shown erratic patterns of swimming, haemorrhage and sudden death. A sample of 28 of these fish with obvious symptoms such as haemorrhages on the skin was selected for detailed histopathological investigation and they were immediately transported live to the laboratory. All animal procedures were performed according to the guide for the care and use of medical laboratory animals of the Ministry of Health, PR China, and with approval of the Ethical Committee of Sichuan Agricultural University.

The gills and body surface were examined microscopically for the presence of parasites. Direct impression smears from the liver tissues of collected fish were fixed with methanol on clean glass slides and stained with Giemsa for 5 min (Duremdez et al. 2004). For bacterial isolation, samples taken from liver, kidney, spleen and brain were directly streaked on Tryptic Soy Agar (TSA) with $5 \%$ sterile sheep's blood and incubated at $30^{\circ} \mathrm{C}$ for $48 \mathrm{~h}$. The pure isolate was tested by using conventional plate and tube tests (Hangzhou Tianhe Microbiological Reagents) (Shen et al. 2005) and the API (Analytical profile index) 20 Strep identification system (BioMerieux) (Barnes and Ellis, 2003). The phylogenetic analysis of the isolated strain was based on 16S rRNA gene sequences, and the lctO gene of Streptococcus iniae was amplified according to Mata et al. ( 2004). Liver, gills, spleens, kidneys, brain and intestines were fixed in $10 \%$ neutral buffered formalin, embedded in paraffin wax, sectioned at $5 \mu \mathrm{m}$ thickness and stained with haematoxylin and eosin (H\&E) following the procedures described by Wang et al. (2000). Some tissue sections were also Gram stained to demonstrate bacteria. Images were recorded on a 11.2 color Mosaic (Diagnostic) camera mounted on a Nikon eclipse 50i (Nikon) microscope. Figs. 1 to 5 show representative images from the sampled fish.

\section{RESULTS}

The pure isolates were mainly isolated from livers, kidneys and spleen of 28 channel catfish samples in the laboratory. Biochemical and phylogenetic (16S rRNA gene) characterization revealed that the pathogen of streptococcus infection in this commercial aquaculture farm in Guangxi Province was Streptococcus iniae (Chen et al. 2011). All diseased fish were listless, sluggish near the water surface, and refused food uptake in the field. A majority $(65.9 \%)$ displayed marked petechial haemorrhages around their lower jaw, ventral abdomen and anus, and in the gills and the dorsal, pectoral, and ventral fins (Fig. 1a). Discoloration at the edge of the fins was also observed $(57.2 \%)$. All visceral organs showing signs of haemorrhage and/or discoloration were congested or swollen; this was particularly marked in the liver, spleen, and kidneys (Fig. 1b). Notably, spleens were dark in color and there was a significant splenomegaly. Other symptoms observed included the presence of ascites $(25.5 \%$, and flaccid intestines filled with a yellowish fluid $(55.3 \%)$. However, some moribund fish $(20.7 \%)$ had no obvious symptoms. No fish had marked ocular changes.

Histological examination of the liver revealed the presence of severe hepatitis. Blood vessels inside the livers of infected channel catfish contained numerous
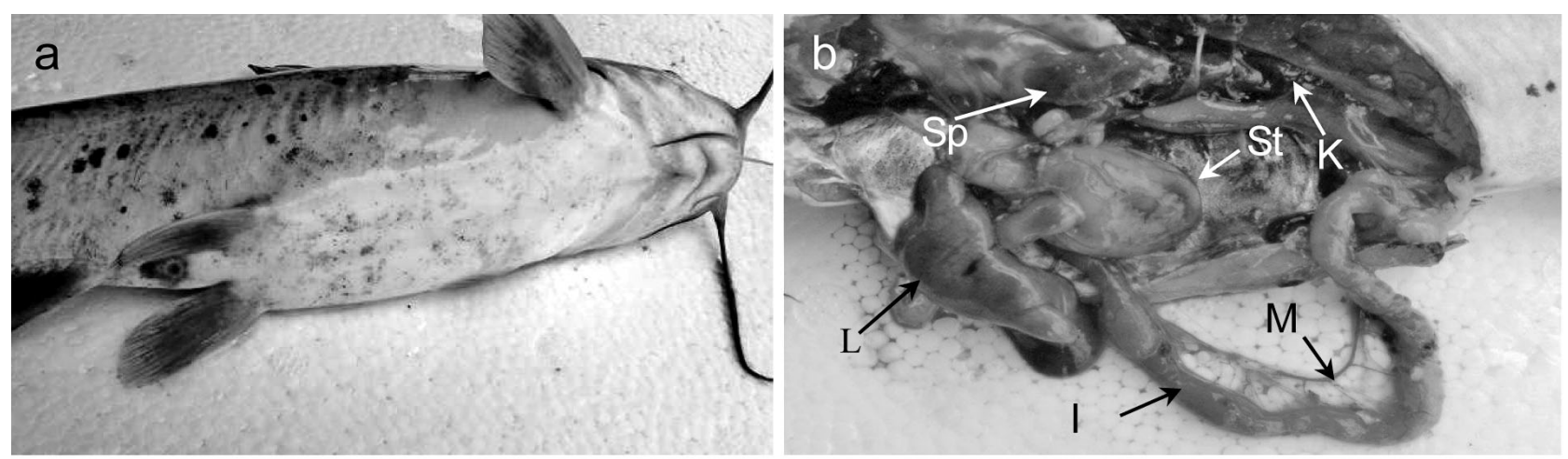

Fig. 1. Ictalurus punctatus. Anatomic examination of channel catfish spontaneously infected with Streptococcus iniae. (a) Marked congestion and hemorrhage in the abdomen, ventral and pectoral fins. (b) Congestion and haemorrhage of visceral organs. L: liver; Sp: spleen; I: intestine; M: mesentery; St: stomach; K: kidney 

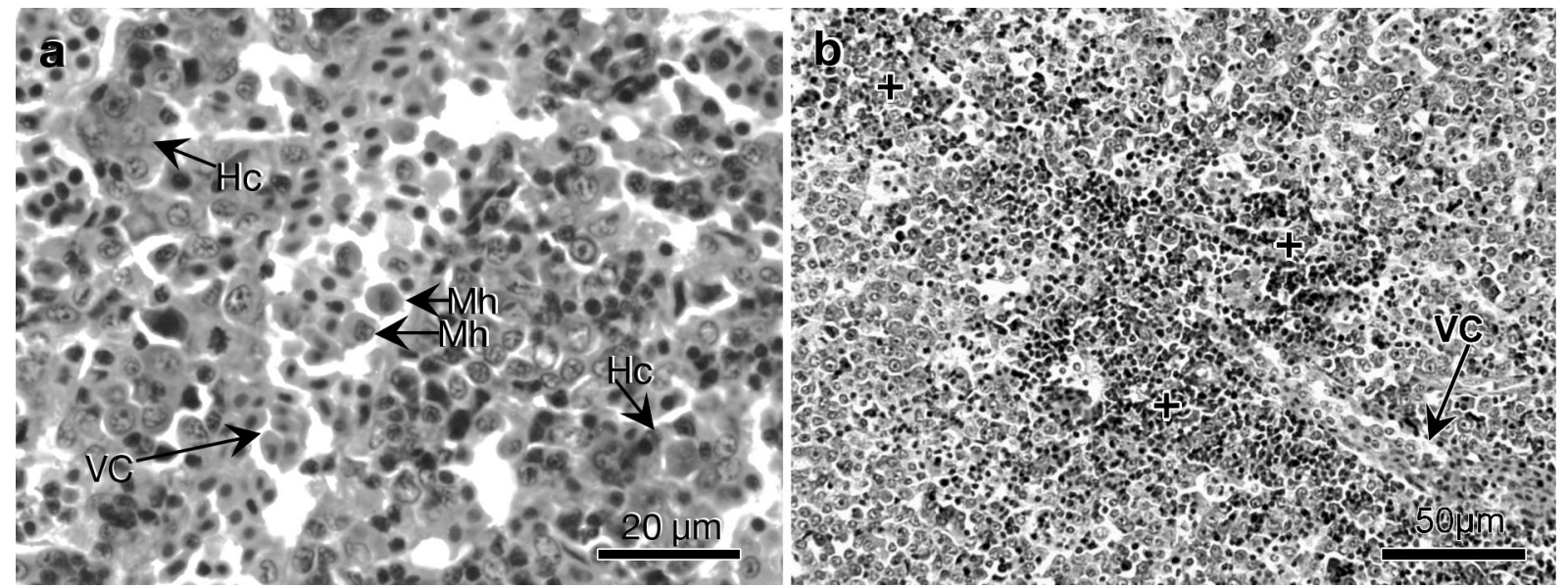

Fig. 2. Ictalurus punctatus. Histological analysis of the liver of channel catfish spontaneously infected with Streptococcus iniae. (a) Large numbers of monocytes (Mh) were present in the blood. Degenerated hepatocytes (Hc) were around the blood vessels. There were numerous macrophages and neutrocyte infiltrations. (b) Aggregation of many inflammatory cells (+) around the congested blood vessel. VC: Vascular congestion. Staining: H\&E

monocytes (Fig. 2b). The hepatocytes around the congested blood vessels showed oedema and necrotic change. There were focal accumulations of numerous macrophages and neutrocytes in the liver (Fig. 2a), indicating a severe inflammatory response. Within this lesion, the inflammatory cells displaced most of the liver tissue, but scattered hepatocytes were still present.

Similarly, there was a marked interstitial nephritis in the kidneys. Histologically, there were many congested blood vessels in the renal interstitium, with numerous inflammatory cells, indicating septicemia (Fig. 3a). The interstitial tissue showed a focal haemorrhagic condition, oedema, and necrotic change, including inflammatory cell responses. Pyknotic and karyorrhectic nuclei were observed in the renal tu- bules and haemopoietic tissue (Fig. 3b). The renal tubules were ruptured.

Analysis of the spleens indicated changes in the architecture. The number of lymphocytes in the white pulp decreased, while the number of macrophages increased (Fig. 4a). Many melano-macrophage centres were formed. Bacteria ingested by macrophages were visible at a higher magnification of the blood vessels in the spleen (Fig. 4b). Together, these data indicated that infection with Streptococcus iniae caused severe splenitis in channel catfish.

The gills appeared hyperemic, and the respiratory epithelial tissue was diffusely detached from the supporting pillar cells. Desquamation of the lamellar epithelial cells and inflammatory cell infiltration were
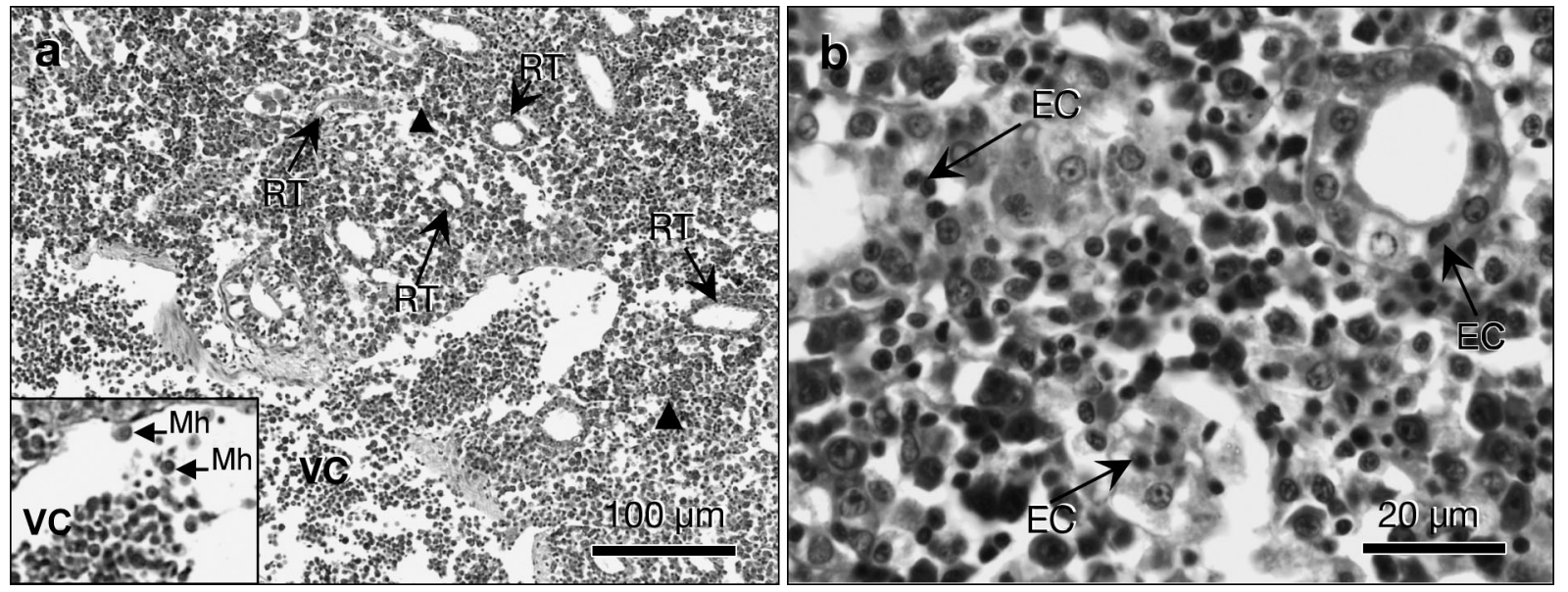

Fig. 3. Ictalurus punctatus. Histological analysis of the kidney of channel catfish spontaneously infected with Streptococcus iniae. (a) Congested interstitial blood vessels (VC) with monocytes (Mh). Note the inflammatory oedema ( $\boldsymbol{\Delta}$ ) among the renal tubules (RT). (b) Renal tubular epithelial cells (EC) showing degeneration and necrosis. Staining: H\&E 

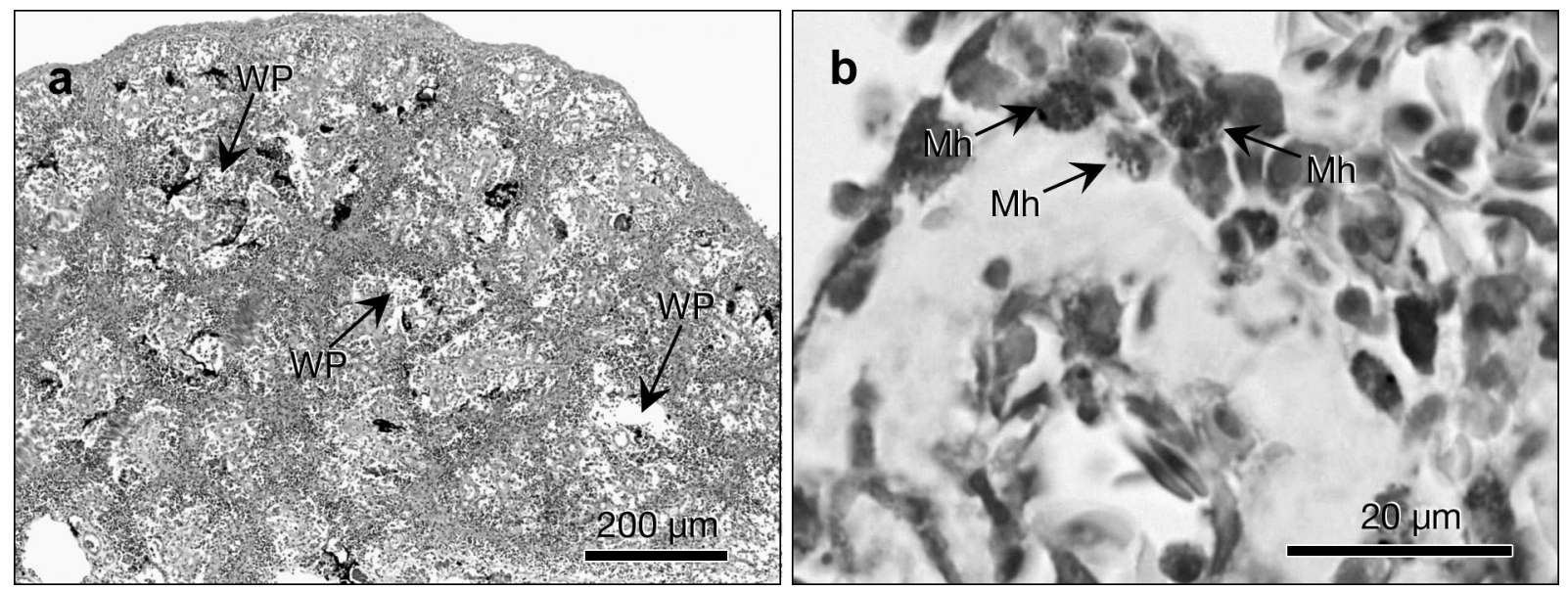

Fig. 4. Ictalurus punctatus. Histological analysis of the spleen of channel catfish spontaneously infected with Streptococcus iniae, showing (a) reduced lymphocyte numbers in the white pulp (WP) and (b) bacterial phagocytosis by macrophages (Mh). Staining: (a) H\&E, (b) Gram stain

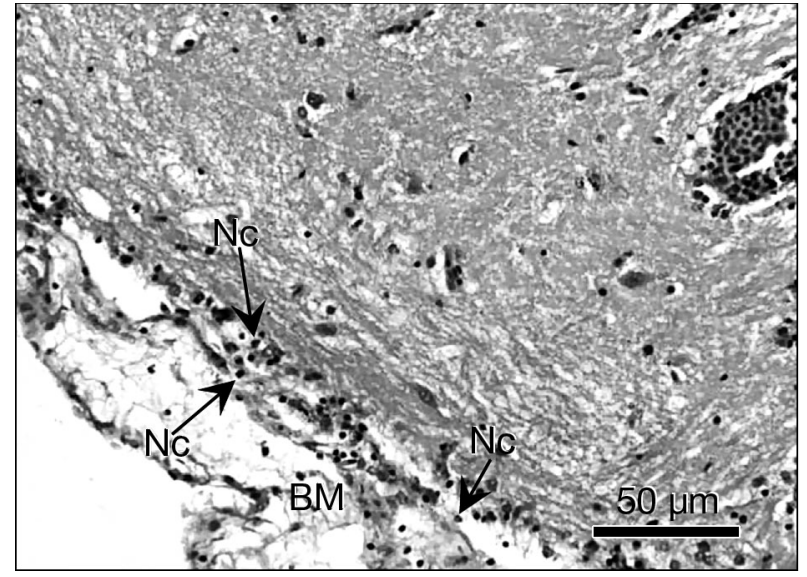

Fig. 5. Ictalurus punctatus. Histological analysis of brain meninges (BM) of channel catfish spontaneously infected with iniae showing neutrocyte $(\mathrm{Nc})$ infiltrates. Staining: H\&E

observed in the lamellae. Similar inflammatory cell infiltration was observed in the lamina propria and the epithelial layer in the intestine of fish. Although there was no obvious lesion of the brain parenchyma, except for scattered neutrocyte infiltration in the meninges (Fig. 5), some blood vessels in the meninges and intestines were severely congested.

\section{DISCUSSION}

Streptococcus iniae has emerged as one of the most important bacteria infecting warm water aquaculture animals and fish, leading to huge economic losses worldwide. It can cause different diseases, depending on the host species infected. Previous studies have shown that $S$. iniae infection can cause multifocal subcutaneous abscesses in dolphins Inia geoffrensis (Pier \& Madin 1976, Pier et al. 1978, Bonar \& Wagner 2003), and skin lesions and necrotizing myositis in red drum Sciaenops ocellatus (Eldar et al. 1999). In barramundi Lates calcarifer, $S$. iniae infection induces systemic and necrotizing inflammation (Creeper \& Buller 2006) and, in tilapia, meningoencephalitis and panophthalmitis (Eldar et al. 1995, Chen et al. 2007). Interestingly, a few studies have shown that $S$. iniae infection causes bacteremic cellulitis in humans (Lau et al. 2003, Facklam et al. 2005). The range of different diseases caused by $S$. iniae infection can be attributed to the variety of host species and to environmental factors.

Until now, Streptococcus iniae has not been considered a common pathogen of channel catfish. However, our previous study reported an outbreak of $S$. iniaeinduced streptococcosis in cultured channel catfish (Chen et al. 2011). In this study, we examined the pathogenic characteristics of spontaneous $S$. iniae infection in channel catfish and found it caused acute septicemia, leading to death.

We observed that channel catfish spontaneously infected with Streptococcus iniae exhibited abnormal behavior in the form of erratic swimming, lethargy and cutaneous hemorrhages, consistent with clinical signs observed in the $S$. iniae-infected red-tail black shark Epalzeorhynchos bicolor and rainbow shark E. erythrurus (Russo et al. 2006). Histopathological examination of visceral organs revealed that the $S$. iniae-infected channel catfish developed necrotizing hepatitis, splenitis, interstitial nephritis and meningitis. The latter was consistent with the clinical symptoms, since meningitis can result in erratic swimming (Chang \& Plumb 1996). The severe splenitis may be 
due to the high capability of the spleen to trap bacteria, because streptococci can be commonly observed in this organ in conjunction with tissue necrosis (Ferguson et al. 1994, Perera et al. 1998). These observations indicate that $S$. iniae can cause a systemic infection associated with a strong inflammatory response in the host, which is in accordance with reports in other species of fish (Perera et al. 1998, Soltani et al. 2005, Russo et al. 2006). However, we did not observe endophthalmitis and granulomas in channel catfish spontaneously infected with $S$. iniae, although these pathogenic symptoms have been reported in other fish (Eldar et al. 1995, Chen et al. 2007). These differences may stem from variations in genetic susceptibility and/or environmental factors. Notably, we observed many macrophage infiltrates in different affected organs, suggesting that macrophages are the main inflammatory mediators in S. iniae-infected channel catfish (Chang \& Plumb, 1996). The simultaneous development of multiple-organ lesions indicates that spontaneous infection with $S$. iniae causes acute systemic inflammation in channel catfish, always leading to sudden death.

There are 2 serotypes of Streptococcus iniae. A previous study has shown that infection with serotype I $S$. iniae tends mainly to cause neural lesions, while infection with serotype II $S$. iniae predominately induces systemic inflammation, affecting multiple organs with diffuse internal haemorrhages (Bachrach et al. 2001). We found that the $S$. iniae-infected channel catfish displayed systemic inflammation, which suggests that the pathogen is likely to be serotype II of $S$. iniae. Previous studies in China have reported $S$. iniae infection in red drum (Shen et al. 2005), tilapia (Gan et al. 2007), and channel catfish (Yu et al. 2008, Chen et al. 2011). Our findings extend our understanding of the pathogenesis of $S$. iniae infection in channel catfish. Further investigation is required to identify the serotype of $S$. iniae that is currently spreading in China and to shed light on how the $S$. iniae infection is transmitted.

Acknowledgements. This work was supported by the Program for Changjiang Scholars and Innovative Research Team in University (no. IRT0848), Animal Loemia Monitoring, Prevention and Treatment Project of the Ministry of Agriculture, China (No.2130108), and the Science and Technology Project of Sichuan Province (No. 08ZA082).

\section{LITERATURE CITED}

Bachrach G, Zlotkin A, Hurvitz A, Evans DL, Eldar A (2001) Recovery of Streptococcus iniae from diseased fish previously vaccinated with a streptococcus vaccine. Appl Environ Microbiol 67:3756-3758

Barnes AC, Ellis AE (2003) Variation in arginine dihydrolase activity in Streptococcus iniae may be an artefact of the assay. Bull Eur Assoc Fish Pathol 23:163-166

Bonar CJ, Wagner RA (2003) A third report of 'golf ball disease' in an Amazon River dolphin (Inia geoffrensis) associated with Streptococcus iniae. J Zoo Wildl Med 34: 296-301

Chang PH, Plumb JA (1996) Histopathology of experimental Streptococcus sp. infection in tilapia, Oreochromis niloticus (L.), and channel catfish, Ictalurua punctatus (Rafinesque). J Fish Dis 19:235-241

Chen CY, Chao CB, Bowser PR (2007) Comparative histopathology of Streptococcus iniae and Streptococcus agalactiae-infected tilapia. Bull Eur Assoc Fish Pathol 27:2-9

Chen DF, Wang KY, Geng Y, Wang J, Huang LY, Li JM (in press) (2011) Streptococcus iniae, isolated from Channel Catfish (Ictalurus punctatus) in China. Isr J AquacultBAMID 63:593-599

Creeper JH, Buller NB (2006) An outbreak of Streptococcus iniae in barramundi (Lates calcarifera) in freshwater cage culture. Aust Vet J 84:408-411

Duremdez R, Al-Marzouk A, Qasem JA, Al-Harbi A, Gharabally H (2004) Isolation of Streptococcus agalactiae from cultured silver pomfret, Pampus argenteus (Euphrasen), in Kuwait. J Fish Dis 27:307-310

Eldar A, Benjerano Y, Livoff A, Horovitcz A, Bercovier H (1995) Experimental streptococcal meningo-encephalitis in cultured fish. Vet Microbiol 43:33-40

Eldar A, Perl S, Frelier PF, Bercovier H (1999) Red drum Sciaenops ocellatus mortalities associated with Streptococcus iniae infection. Dis Aquat Org 36:121-127

Facklam R, Elliott J, Shewmaker L, Reingold A (2005) Identification and characterization of sporadic isolates of Streptococcus iniae isolated from humans. J Clin Microbiol 43:933-937

Ferguson HW, Morales JA, Ostland VE (1994) Streptococcosis in aquarium fish. Dis Aquat Org 19:1-6

Gan X, Chen M, Yu XL, Li LP and others (2007) Sequencing and phylogenetic analysis of the 16S rRNA gene of Streptococcus iniae. J Fish Chn 31:618-623 (in Chinese with English Abstract)

Lahav D, Eyngor M, Hurvitz A, Ghittino C, Lublin A, Eldar A (2004) Streptococcus iniae type II infections in rainbow trout Oncorhynchus mykiss. Dis Aquat Org 62:177-180

Lau SKP, Woo PCY, Tse H, Leung KW, Wong SSY, Yuen KY (2003) Invasive Streptococcus iniae infections outside North America. J Clin Microbiol 41:1004-1009

- Mata AI, Blanco MM, Domínguez L, Fernández-Garayzábal JF, Gibello A (2004) Development of a PCR assay for Streptococcus iniae based on the lactate oxidase (lctO) gene with potential diagnostic value. Vet Microbiol 101: 109-116

Perera RP, Fiske RA, Johnson SK (1998) Histopathology of hybrid tilapias infected with a biotype of Streptococcus iniae. J Aquat Anim Health 10:294-299

> Pier GB, Madin SH (1976) Streptococcus iniae sp. nov., a betahemolytic Streptococcus from an Amazon freshwater dolphin (Inia geoffrensis). Int J Syst Bacteriol 26:545-553

> Pier GB, Madin SH, Al-Nakeeb S (1978) Isolation and characterization of a second isolate of Streptococcus iniae. Int J Syst Bacteriol 28:311-314

Robinson JA, Meyer FP (1966) Streptococcal fish pathogen. J Bacteriol 92:512

Russo R, Mitchell H, Yanong RPE (2006) Characterization of Streptococcus iniae isolated from ornamental cyprinid fishes and development of challenge models. Aquaculture 256:105-110

Shen ZH, Qian D, Xu WJ, Gu JH, Shao JZ (2005) Isolation, identification and pathogenicity of Streptococcus iniae 
isolated from red drum Sciaenops ocellatus. Acta Hydrobiol Sinica 29:678-683 (in Chinese with English Abstract) Shoemaker CA, Klesius PH, Evans JJ (2001) Prevalence of Streptococcus iniae in tilapia, hybrid striped bass, and channel catfish on commercial fish farms in the United States. Am J Vet Res 62:174-177

Soltani M, Jamshidi S, Sharifpour I (2005) Streptococcosis caused by Streptococcus iniae in farmed rainbow trout (Oncorhynchus mykiss) in Iran: biophysical characteristics and pathogensis. Bull Eur Assoc Fish Pathol 25:95-106

Editorial responsibility: Thomas Braunbeck, Heidelberg, Germany
Wang BY, Li YS, Huang GS, Zhang YQ (2000) Pathological techniques. People's Medical Publishing House, Beijing (in Chinese)

Wang KY, Geng Y, Chen DF, Huang JL (2008) An overview of channel catfish major diseases and disease control. Scientific Fish Farming 217(1):14-16 (in Chinese)

Yu XL, Chen M, Li C, Li LP, Lei AY, Zhong MN, Liang WW (2008) Channel catfish Ictalurus punctatus outbreak infected by bacterium Streptococcus iniae. J Dalian Fish Univ 23:680-686 (in Chinese with English Abstract)

Submitted: September 21, 2010; Accepted: March 3, 2011 Proofs received from author(s): June 6, 2011 